\title{
PSORÍASE EM PLACAS EM DOENTE COM SÍNDROME DE DOWN - POTENCIAL PATOFISIOLOGIA COMUM E DIFICULDADE DE TRATAMENTO
}

\author{
Catarina Araúio', Cristina Resende', Ana Paula Vieira², José Carlos Fernandes², Celeste Brito ${ }^{3}$ \\ 'Interna do Internato Complementar de Dermatologia e Venereologia/Resident, Dermatology and Venereology \\ ${ }^{2}$ Assistente Hospitalar Graduado de Dermatologia e Venereologia/Consultant, Dermatology and Venereology \\ ${ }^{3}$ Chefe de Serviço, Directora do Serviço de Dermatologia e Venereologia/Consultant Chief, Head of Department of \\ Dermatology and Venereology \\ Serviço de Dermatologia e Venereologia, Hospital de Braga, Sete Fontes - São Victor, Braga, Portugal
}

\begin{abstract}
RESUMO - Introdução: A psoríase ocorre em até 8\% dos doentes com síndrome de Down e, embora mal caraterizada, parece estar correlacionada com desequilíbrio imunológico das células Th le alterações bioquímicas nos nucleótidos cíclicos. Caso clínico: Doente do sexo feminino, 38 anos, com síndrome de Down e antecedentes de psoríase (PASI inicial de 30) desde os 18 anos de idade. Medicada com ciclosporina e metotrexato e subsequentemente foi medicada com etanercept, adalimumab e ustecinumab por perda progressiva de resposta (PASI atual de 10). Conclusão: Descreve-se este caso pela má resposta aos tratamentos, incluindo diversos agentes biológicos. A potencial baixa adesão à terapêutica e a disfunção imunológica poderão limitar as opções terapêuticas.
\end{abstract}

PALAVRAS-CHAVE - Anticorpos monoclonais; Psoríase; Síndrome de Down.

\section{PLAQUE PSORIASIS IN A PATIENT WITH DOWN SYNDROME - POTENTIAL COMMON PATHOPHYSIOLOGY AND TREATMENT DIFFICULTY}

ABSTRACT - Introduction: Psoriasis occurs in up to $8 \%$ of patients with Down syndrome and, although poorly characterized, appears to be correlated with immune imbalance in cells Th 1 and biochemical changes of cyclic nucleotides. Case report: Female patient, 38 years old, with Down syndrome and psoriasis (initial PASI 30) since 18 years. Initially treated with cyclosporine and methotrexate and subsequently with etanercept, adalimumab and ustecinumab because of progressive loss of response (current PASI 10). Conclusion: We describe this case for the poor response to treatment including various biological agents. Potential poor adherence to therapy and immune dysfunction may limit the therapeutic options.

KEY-WORDS - Antibodies, monoclonal; Down syndrome; Psoriasis.

Conflitos de interesse: Os autores declaram não possuir conflitos de interesse.

No conflicts of interest.

Suporte financeiro: O presente trabalho não foi suportado por nenhum subsídio ou bolsa.

No sponsorship or scholarship granted.

Direito à privacidade e consentimento escrito / Privacy policy and informed consent: Os autores declaram que pediram consentimento ao doente para usar as imagens no artigo. The authors declare that the patient gave written informed consent for the use of its photos in this article.

Recebido/Received - Setembro/September 2014; Aceite/Accepted - Outubro/October 2014 


\section{Caso Clínico}

Dr. . Catarina Araújo
Serviço de Dermatologia e Venereologia
Hospital de Braga, Sete Fontes - São Victor
4710-243 Braga, Portugal.
Tel.: +351-253-027-000
Fax: +351-253-027-999
E-mail: catarina.portela.araujo@gmail.com

\section{INTRODUÇÃO}

A síndrome de Down (trissomia do cromossoma 21) é a doença cromossómica mais comum com alterações físicas e psicológicas bem conhecidas. As manifestações cutâneas incluem xerose (85\%), tinea pedis $(76 \%)$, onicomicose $(67 \%)$, dermatite atópica $(56 \%)$, siringomas $(39 \%)$, dermatite seborreica $(36 \%)$, acne vulgar $(10 \%)$, alopécia areata $(9 \%)$, cútis marmorata (8\%), anetodermia, vitiligo, escabiose, elastose serpiginosa perfurante, psoríase, pitiríase rubra pilar e líquen plano'. A incidência de psoríase é comum, ocorrendo em até $8 \%$ dos doentes com síndrome de Down ${ }^{2,3}$. A associação entre as duas doenças, embora mal caraterizada, parece estar correlacionada com desequilíbrio imunológico associado às células Th $1 \mathrm{e}$ alterações bioquímicas nos nucleótidos cíclicos. Apesar da informação publicada ser limitada, a utilização de agentes biológicos tem demonstrado eficácia e segurança no tratamento destes doentes. Descreve-se uma doente com síndrome de Down e psoríase com tratamento sistémico de longa duração, incluindo diversos agentes biológicos.

\section{CASO CLÍNICO}

Doente do sexo feminino, 38 anos, com síndrome de Down e antecedentes de psoríase desde os 18 anos de idade. Clinicamente com placas eritemato-descamativas na face, tronco e membros e envolvimento articular com anos de evolução de remissões e exacerbações. Sem história medicamentosa ou infeções recentes. Sem história familiar de patologia cutânea ou síndrome de Down. Doente com oligofrenia ligeira, institucionalizada mas com atividades sociais regulares. Inicialmente ao exame objectivo apresentava múltiplas pápulas e placas eritematosas com escama prateada e aderente no couro cabeludo, na face, na região retro-auricular, no tronco e na face extensora dos membros (palmas e plantas poupadas) com (PASI
30); hiperceratose sub-ungueal e xerose cutânea generalizada. Fenómeno de Koebner e sinal de Auspitz eram positivos. Medicada durante alguns anos com agentes tópicos (coaltar, calcipotriol e corticosteróides) e ciclosporina e metotrexato em esquema sequencial e rotativo que se tornaram ineficazes no controlo da doença. Subsequentemente, após falha do tratamento convencional e, após screening adequado foi medicada com etanercept $50 \mathrm{mg} / \mathrm{semana}$ durante um ano com boa resposta clínica durante os primeiros 6 meses e posteriormente switch para adalimumab $40 \mathrm{mg} \mathrm{a}$ cada 2 semanas durante 6 meses. Por perda progressiva de resposta foi realizada o switch para ustecinumab 45 mg (0,4 e 12 semanas) com melhoria clínica significativa após o primeiro mês mas perda de eficácia ao longo de 6 meses. Actualmente em tratamento com ustecinumab ao qual foi acrescentado metotrexato $10 \mathrm{mg} / \mathrm{semana}$, mantendo ainda lesões embora menos infiltradas principalmente no tronco e membros inferiores (PASI atual de 15) (Fig.s 1 e 2). Não foram observados eventos adversos durante todo o período de tratamento.

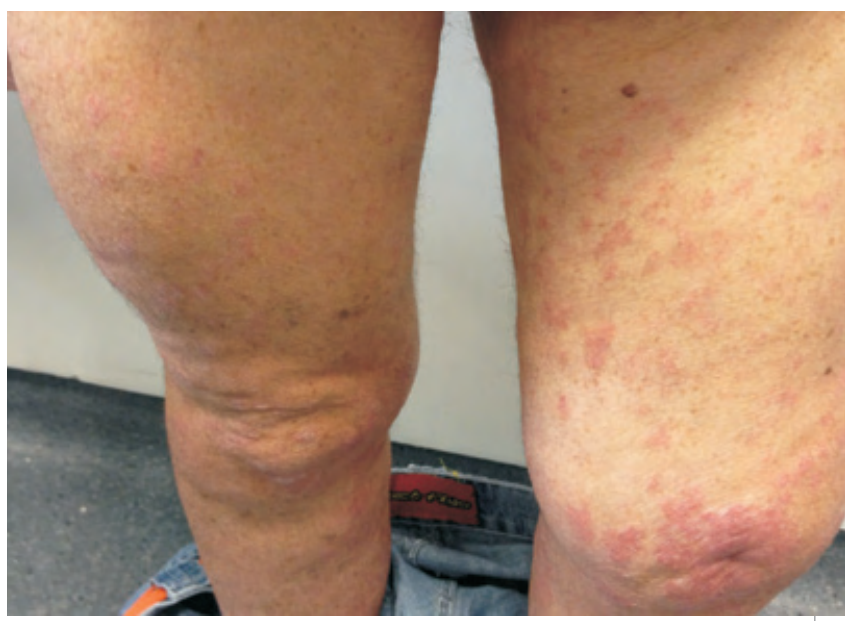

Fig. 1 - Psoríase em placas nos membros inferiores após tratamento com ustekinumab e metotrexato. 


\section{Caso Clínico}

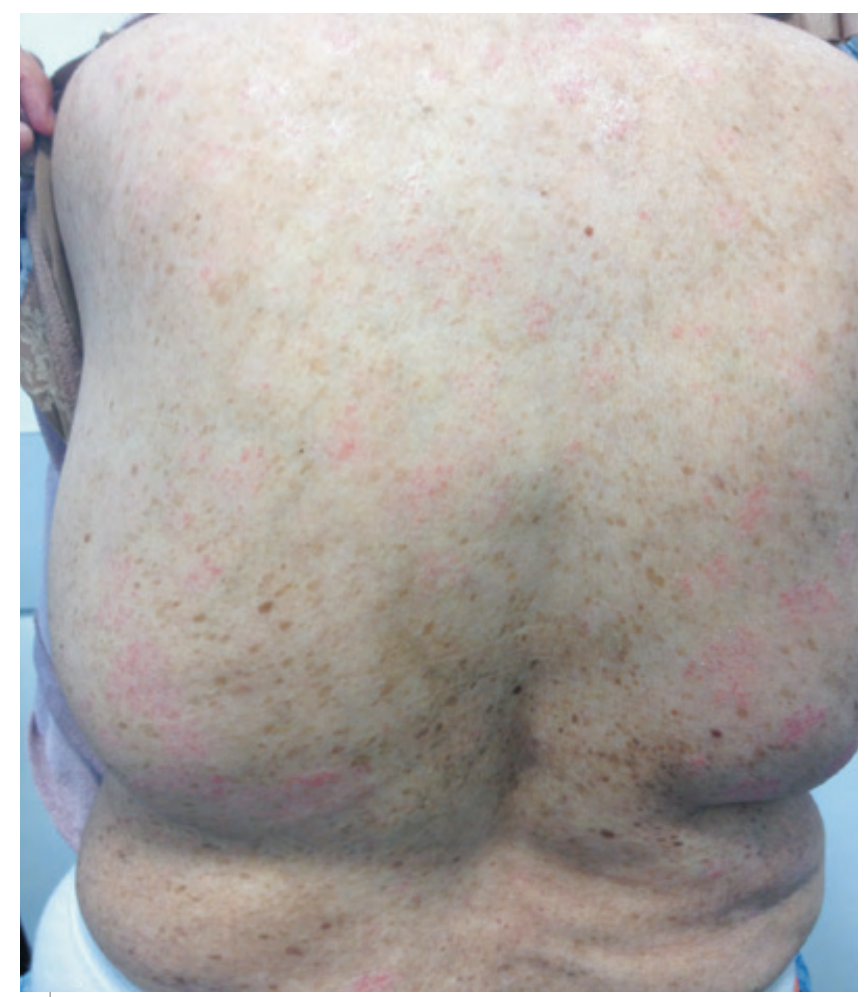

Fig 2 - Placas eritematodescamativas no dorso menos infiltradas e descamativas após tratamento com ustekinumab e metotrexato.

\section{DISCUSSÃO}

Apesar de ser comum a presença concomitante de psoríase e síndrome de Down apenas estão descritos poucos casos clínicos na literatura ${ }^{4-7}$, incluindo a associação a artropatia psoriática ${ }^{8}$.

A psoríase é uma doença multifatorial com determinação genética e influência ambiental. A alteração cromossómica pode contribuir quer para a etiologia quer para a expressão da doença.

Apesar de não haver ligação direta entre síndrome de Down e via Th 17, há dados suportando a desregulação de interferão (IFN) nestes doentes ${ }^{9}$. A percentagem de células Th 1 e níveis séricos de IFN-y em doentes com $\mathrm{S}$. de Down é significativamente maior ${ }^{10}$. A ação de IFN-y requer a ligação ao recetor IFNGR-1 codificado no braço longo do cromossoma 6 e um fator acessório IFNGR-2 codificado no cromossoma 21 , proporcionando aumento da sensibilidade ao IFN ${ }^{10,11}$.

Por outro lado, a psoríase está associada com diminuição de monofosfato de adesonina cíclica (cAMP) e aumento de monofosfato de guanosina cíclica (cGMP), alterações comuns nos nucleótidos cíclicos de doentes com S. de Down. cGMP é formado pela ação de guanilato ciclase que é estimulada pela enzima superóxido dismutase I (codificada na região 21 q22.11). Tem sido sugerido que a proliferação celular é estimulada quer pela redução de cAMP quer pelo aumento de cGMPo,12.

A associação entre psoríase e síndrome de Down realça a importância da relação entre alterações genéticas e imunidade. O tratamento destes doentes pode ser difícil não só pelo risco de toxicidade órgão específica mas também pela maior suscetibilidade a infeções e maior incidência de malignidade nestes doentes. Tem sido discutido a segurança e eficácia de agentes biológicos no tratamento de doentes com síndrome de Down e psoríase ${ }^{4,13}$.

Por outro lado, estas crianças são mais susceptíveis a apresentar alteração na qualidade de vida devido ao paradigma social que estabelece a incapacidade mediante a presença da deficiência física e intelectual, neste caso, agravado pela presença de dermatose, por si só, descriminada socialmente. A dificuldade de comunicação e compreensão de sintomas, a potencial baixa adesão ao tratamento, incluindo tópicos, e a presença de fatores co-agravantes da dermatose como a xerose cutânea, o prurido e o fenómeno de Koebner são condicionantes a ter em conta na observação destes doentes.

Descreve-se este caso pela má resposta aos tratamentos, incluindo diversos agentes biológicos. Nesta doente, perante o mau controlo da doença e falha do tratamento convencional, o próximo passo foi iniciar tratamento com agentes biológicos, nomeadamente etanercept. Por resposta clínica com variação de PASI $<50$, foi realizado switching por outro agente biológico diferente. Após falha de dois agentes anti-TNF $\alpha$, optou-se por ustecinumab e posteriormente pela associação com outro agente sistémico, metotrexato. Não foram registados efeitos laterais adversos durante todo o tratamento.

\section{CONCLUSÃO}

São necessários mais dados que possam clarificar a patogénese das duas doenças. Só assim se poderá melhorar as estratégias terapêuticas e a qualidade de vida destes doentes.

A potencial baixa adesão à terapêutica, a presença de muitas co-morbilidades e alterações congénitas e a disfunção imunológica poderão ser limitações a considerar nas opções terapêuticas nos doentes com psoríase e síndrome de Down. 


\section{Caso Clínico}

\section{BIBLIOGRAFIA}

1. Carter M, Jegasothy BV. Alopecia areata and Down syndrome. Arch Dermatol. 1976; 112:1397-9.

2. Polenghi MM, Plattoni F, Orsini GB, et al. Dermatologic disorders in Down syndrome. Am J Med Genet 1990; 7(suppl): 324.

3. Madan V. Dermatological manifestations of Down's syndrome. Clin Exp Dermatol. 2006; 31:623-9.

4. Alcaide AJ. Safety of etanercept therapy in a patient with psoriasis, Down's syndrome and concomitant hepatitis $C$ virus infection. J Eur Acad Dermatol Venereol. 2008; 22:1514-6.

5. Fargnoli MC. Psoriasis, Kaposi's sarcoma and Hodgkin's disease in a patient with Down's syndrome. Dermatology. 2004; 209:158-9.

6. Mariyath OR. Unstable Psoriasis in Down's Syndrome. Indian J Dermatol Venerol Leprol. 2003; 69:61-3.

7. Marmon S, Souza A, Strober B. Psoriasis and Down syndrome: A report of three cases and a potential pathophysiologic link. Dermatol Online J. 2012;
18(6):13.

8. Ihnat Dk, Simpson GM, Conard K, Scott Cl, Singsen $\mathrm{BH}$. Inflammatory arthropathies in children with chromosomal abnormalities. J Rheumatol.1993; 20:742-6.

9. Maroun LE. Interferon action and chromosome 21 trisomy (Down syndrome): 15 years later. J Theor Biol. 1996; 181:41-6.

10. Torre D. Serum levels of gamma interferon in patients with Down's syndrome. Infection. 2005; 23(1):66-7.

11. Maroun LE. Interferon effect on ribosomal ribonucleic acid related to chromosome 21 ploidy. Biochem J. 1979; 179: 221-5.

12. Karlsson JO, Sjostedt A, Wahlstrom J, Axelsson KL, Andersson RG. Cyclic guanosine monophosphate metabolism in human amnion cells trisomic for chromosome 21. Biol Neonate. 1990; 57:343-8.

13. Talamonti M, Galluzzo M, Chiricozzi A, Teoli M, Bavetta $M$, Costanzo $A$ et al. Ustekinumab for treatment of plaque psoriasis in a patient with Down syndrome. J Drugs Dermatol. 2012; 11 (8):1000-2. 